\title{
ALTERAÇÕES FÍSICAS E MICROBIOLÓGICAS DURANTE A COMPOSTAGEM DOS DEJETOS DE CABRAS ${ }^{1}$
}

\section{ANA C. A. ORRICO ${ }^{2}$, JORGE DE LUCAS JÚNIOR ${ }^{3}$, MARCO A. P. ORRICO JÚNIOR ${ }^{4}$}

RESUMO: Avaliaram-se as reduções de massa seca enleirada, volume ocupado pelas leiras e coliformes durante a compostagem dos dejetos gerados por cabras Saanen e F1 (Saanen x Boer), alimentadas com três dietas (dieta $1=80 \%$ volumoso $(\mathrm{V})$ e $20 \%$ concentrado $(\mathrm{C})$; dieta $2=60 \% \mathrm{~V}$ e $40 \% \mathrm{C}$, e dieta $3=40 \% \mathrm{~V}$ e $60 \% \mathrm{C})$. As maiores reduções $(\mathrm{P}<0,05)$ nas quantidades de massa seca ocorreram em leiras formadas com os dejetos gerados por cabras alimentadas com a dieta 3 $(56,2 \%)$, em relação aos dejetos gerados quando consumiram as dietas $2(44,5 \%)$ e $1(40,6 \%)$. A maior média da temperatura semanal ocorreu na primeira semana, em leiras formadas a partir dos dejetos de cabras que consumiram a dieta 3. As leiras preparadas com dejetos produzidos por cabras alimentadas com a dieta 1 mantiveram a temperatura superior por maior período de tempo $\left(50,75^{\circ} \mathrm{C}\right.$, na terceira semana), em relação às originadas de cabras alimentadas com as dietas 2 e 3 (45,90 e $42{ }^{\circ} \mathrm{C}$, respectivamente, no mesmo período). As reduções de coliformes totais e fecais foram de, no mínimo, 99,99\%. As reduções de volume, em função do tempo, geraram equações quadráticas em todas as condições.

PALAVRAS-CHAVE: leiras, patógenos, reciclagem.

\section{PHYSIC AND MICROBIOLOGICAL MODIFICATIONS DURING COMPOSTING OF GOATS MANURE}

\begin{abstract}
This work aimed at to evaluate the dry mass, volume and coliforms reductions during the composting of the manure generated by Saanen and F1 (Saanen Boer x) goats, fed with three diets (diet $1=80 \%$ forage $(\mathrm{F})$ and $20 \%$ concentrated $(\mathrm{C})$; diet $2=60 \% \mathrm{~F}$ and $40 \% \mathrm{C}$, and diet $3=40 \% \mathrm{~F}$ and $60 \% \mathrm{C}$ ). The largest reductions $(\mathrm{P}<0.05)$ of the amounts of dry mass occurred in piles formed with the manure generated by goats fed with diet $3(56.2 \%)$, in relation to the manure produced when the animals consumed the diets $2(44.5 \%)$ and $1(40.6 \%)$. The largest average of the weekly temperature occurred in the first week in piles formed with goat manure that consumed diet 3. The originated piles of goat manure feed with diet 1 maintained the superior temperature for longer time $\left(50.75{ }^{\circ} \mathrm{C}\right.$, in the third week), in relation to those originated from goats fed by diets 2 and 3 (45.90 and $42.00{ }^{\circ} \mathrm{C}$, respectively, in the same period). The reductions of total and fecal coliforms were of $99.99 \%$ minimum. The volume reductions, in time function, generated quadratic equations in all the conditions.
\end{abstract}

KEYWORDS: piles, pathogens, recycle.

\section{INTRODUÇÃO}

A criação de pequenos ruminantes tem sofrido aumentos significativos durante as últimas décadas, sobretudo nos países em desenvolvimento. Esses animais representam importante papel na diversificação da economia, sendo capazes de transformar recursos marginais em produtos de qualidade (carne, leite, lã ou pêlos, couro e esterco). Sob a óptica econômica e ambiental, a produção de pequenos ruminantes seria mais vantajosa do que qualquer outra espécie animal pela

\footnotetext{
${ }^{1}$ Pesquisa financiada pela FAPESP (Processo $\mathrm{n}^{\mathrm{o}}$ 02/12168-9).

${ }^{2}$ Zootecnista, Profa. Doutora, Universidade Católica Dom Bosco, Campo Grande - MS, Fone: (0XX67) 3312.3517, Ramal: 3517 , zoo@ucdb.br

${ }^{3}$ Eng $^{\mathrm{o}}$ Agrônomo, Professor Titular, Departamento de Engenharia Rural, UNESP, Jaboticabal - SP, jlucas@ fcav.unesp.br

${ }^{4}$ Zootecnista, Mestrando pelo Programa de Zootecnia, UNESP - Jaboticabal, Departamento de Engenharia Rural, Fone: (0XX16) 3209.2638. Bolsista da FAPESP.
}

Recebido pelo Conselho Editorial em: 13-7-2006

Aprovado pelo Conselho Editorial em: 19-7-2007 
elevada rusticidade e prolificidade, por contribuir em menores proporções com desgastes do solo (erosão pelo pastejo e/ou demanda de alimento), fácil adaptação, se alimentados com resíduos de colheitas e menor emissão de metano, em relação aos bovinos (EL AICH \& WATERHOUSE, 1999).

No Brasil, o Estado de São Paulo responde pelas mais expressivas produções de leite de cabra, com rebanhos de animais puros das raças Saanen e Alpina, onde, muitas vezes, os machos são descartados logo após o nascimento. Contrastando com essa realidade, existe procura significativa pela carne de caprinos. Esse fato pode justificar a implantação de sistemas que utilizem os cabritos e o excedente das fêmeas na produção de carne, possibilitando, inclusive, a agregação de valor na produção de leite.A introdução de raças produtoras de carne nesses sistemas pode constituir-se em alternativa para o atendimento da demanda. Nesse particular, a raça Boer vem sendo apontada como a de melhor potencial para ser utilizada em cruzamentos com as raças leiteiras (RIBEIRO \& RIBEIRO, 2001).

O emprego da compostagem nos resíduos gerados na criação de caprinos contribui para que haja maior lucratividade da atividade e melhor sustentabilidade de todo o sistema produtivo. Essa prática de reciclagem consiste na otimização da degradação da matéria orgânica contida nos dejetos, com ênfase na qualidade do produto final.

Durante a compostagem, ocorrem duas fases: termofílica $\left(45\right.$ a $\left.65^{\circ} \mathrm{C}\right)$, na qual será máxima a atividade microbiológica de degradação e higienização, e a fase de maturação ou cura, quando ocorrem a humificação e a produção do composto propriamente dito (PEREIRA NETO \& STENTIFORD, 1992). GOMEZ (1998) ressaltou alguns benefícios do processo de compostagem: reciclagem dos elementos com interesse agronômico, redução do volume inicial de resíduos, degradação de substâncias tóxicas e/ou patógenos e conversão dos nutrientes até formas que sejam mais disponíveis às plantas. IMBEAH (1998) evidenciou a importância da conversão de N amoniacal para formas nitrogenadas estáveis.

Independentemente do material que será utilizado como substrato para a compostagem, a USEPA (1996) recomenda que a temperatura no interior da leira atinja, no mínimo, $55^{\circ} \mathrm{C}$ e se mantenha nessa faixa por três dias consecutivos para que o número de patógenos atinja níveis aceitáveis, permitindo a aplicação no solo (esses valores devem ser inferiores a 1.000 coliformes termotolerantes por $\mathrm{kg}$ de produto final).

As elevadas temperaturas alcançadas no início do processo são decorrentes das eficientes taxas de degradação da matéria orgânica, resultando na redução de massa enleirada, volume ocupado pelas leiras e coliformes. Essas transformações ocorrem porque existe a perda de matéria orgânica na forma de $\mathrm{CO}_{2}$ e a produção de ácidos durante o processo, que, além dos benefícios mencionados anteriormente, resultam no aumento da concentração de fração mineral, melhorando, assim, a qualidade do produto final.

AMORIM et al. (2003) utilizaram esterco de cabras Saanen como substrato para a compostagem e observaram que a redução de massa seca foi maior $(\mathrm{P}<0,05)$ em leiras conduzidas durante as estações de verão e outono (54,6 e 51,6\%, respectivamente), em relação às manejadas durante o inverno e a primavera, médias de 49,2 e 48,8\%, respectivamente.

Ao avaliarem a compostagem de mistura obtida a partir dos resíduos de extração de óleo de palma e dejetos de caprinos (90:25 kg, respectivamente), THAMBIRAJAH et al. (1995) obtiveram temperaturas acima de $40^{\circ} \mathrm{C}$ durante os primeiros 25 dias de compostagem, verificando que o pico de temperatura foi de $70{ }^{\circ} \mathrm{C}$ e ocorreu no quarto dia de formação das leiras. Em experimento realizado por HANAJIMA et al. (2001), usando esterco bovino como substrato para formação das leiras, a temperatura máxima observada foi de $65,9^{\circ} \mathrm{C}$.

Baseando-se na relevância da compostagem dos resíduos gerados na criação de caprinos, este trabalho teve o objetivo de avaliar as reduções de massa seca, volume enleirado e coliformes 
durante a compostagem dos dejetos gerados por cabras Saanen e F1 (Saanen x Boer), alimentadas com três dietas.

\section{MATERIAL E MÉTODOS}

O trabalho foi realizado no Laboratório de Digestão Anaeróbia, do Departamento de Engenharia Rural, utilizando-se dos dejetos gerados no Setor de Caprinocultura do Departamento de Zootecnia, ambos pertencentes à UNESP - Câmpus de Jaboticabal.

O clima da região, segundo a classificação de Köeppen, é Cwa, isto é, subtropical úmido, seco no inverno e com chuvas no verão, com precipitação anual em torno de $1.400 \mathrm{~mm}$ e temperatura média anual próxima de $21,5{ }^{\circ} \mathrm{C}$. Os dados meteorológicos referentes aos meses de execução do experimento estão apresentados na Tabela 1.

TABELA 1. Dados meteorológicos mensais do ano de 2003, em Jaboticabal - SP.

\begin{tabular}{lcccccccc}
\hline Mês & $\begin{array}{c}\text { Pressão } \\
(\mathrm{hPa})\end{array}$ & $\begin{array}{c}\text { Tmáx } \\
\left({ }^{\circ} \mathrm{C}\right)\end{array}$ & $\begin{array}{c}\text { Tmín } \\
\left({ }^{\circ} \mathrm{C}\right)\end{array}$ & $\begin{array}{c}\text { Tméd } \\
\left({ }^{\circ} \mathrm{C}\right)\end{array}$ & UR $(\%)$ & $\begin{array}{c}\text { Precipitação } \\
(\mathrm{mm})\end{array}$ & ND & Insolação (h) \\
\hline junho & 946,6 & 28,8 & 14,4 & 20,5 & 69,5 & 12,3 & 2 & 265,4 \\
julho & 948,5 & 27,8 & 12,6 & 19,4 & 60,9 & 17,2 & 3 & 269,1 \\
agosto & 947,0 & 28,4 & 12,3 & 19,6 & 59,0 & 10,6 & 6 & 265,1 \\
setembro & 944,9 & 31,3 & 15,4 & 22,8 & 56,4 & 23,3 & 4 & 246,4 \\
outubro & 943,1 & 31,7 & 17,8 & 24,0 & 60,6 & 66,6 & 10 & 222,7 \\
\hline ano & 944,4 & 30,0 & 17,0 & 22,5 & 69,4 & $1.262,3$ & 114 & $2.834,5$ \\
\hline
\end{tabular}

Pressão: pressão atmosférica; Tmáx: temperatura máxima; Tmín: temperatura mínima; Tméd: temperatura média; UR: umidade relativa do ar; ND: número de dias com chuva.

Dados disponíveis em: http://www4.fcav.unesp.br/departamentos/cienciasexatas/estacao/dadosmeteor.htm

O ensaio foi conduzido utilizando-se dos dejetos gerados por cabras adultas, Saanen e F1 (Saanen x Boer), com aproximadamente 2 anos de idade, em final de lactação ou secas, e com médias de peso de 45,0 e 58,0 kg, para F1 e Saanen, respectivamente. As cabras foram alimentadas com três dietas (dieta $1=80 \%$ volumoso e $20 \%$ concentrado; dieta $2=60 \%$ volumoso e $40 \%$ concentrado, e dieta $3=40 \%$ volumoso e $60 \%$ concentrado).

O volumoso foi o feno de Tifton 85 (Cynodon dactylon), e o concentrado foi composto por: 46,8\% de milho moído; $4,0 \%$ de soja-grão; $11,0 \%$ de farelo de soja; $9,1 \%$ de farelo de algodão; $5,2 \%$ de farelo de trigo; $17,9 \%$ de feno de alfafa; $5,0 \%$ de núcleo leite, e 1,0\% de calcário. Para o cálculo de oferta do volumoso, contabilizou-se o feno de alfafa contido no concentrado. As dietas foram balanceadas para atender às exigências dos animais, segundo recomendações do NRC (1981).

Foram utilizadas 60 cabras, 30 de cada genótipo, alocadas em baias distintas, compostas por piso suspenso com ripado de madeira e canaleta de alvenaria para o acúmulo e a colheita dos resíduos. A alimentação foi mantida a mesma para ambos os grupos, por 20 dias consecutivos, sendo que, ao final desse período, a massa total de dejetos foi coletada das canaletas, e iniciado novo período de alimentação com a dieta subseqüiente. Os dejetos produzidos nos primeiros cinco dias de cada troca de alimentação foram desprezados, para diminuir a ocorrência de contaminação da dieta anterior.

Com os dejetos coletados, foram confeccionadas três leiras por tratamento (Saanen e F1, alimentadas com as dietas 1; 2 e 3), totalizando 18 leiras. As leiras foram formadas após cada 20 dias de alimentação das cabras, sendo a diferença entre a formação das leiras da dieta 1 e dieta 3 de 60 dias, e conduzidas em área coberta com lona plástica, piso de alvenaria e declividade de $2 \%$. Foram adotadas como medidas: 1,0 m para altura e 1,5 m para largura, com comprimento dependente da quantidade de material enleirado. Para a formação das leiras, a massa de dejetos foi previamente peneirada, em peneira com malha de $1,5 \mathrm{~cm}$, para que as cíbalas fossem fracionadas. 
O substrato empregado na formação das leiras consistiu somente dos dejetos, não havendo a mistura de qualquer outro resíduo, sendo a relação C:N inicial de 21,94; 23,96 e 26,22 para as leiras compostas por dejetos de cabras Saanen, alimentadas com as dietas 1; 2 e 3, respectivamente, e de 24,91; 25,52 e 28,13 para as leiras que contiveram os dejetos produzidos por cabras F1, alimentadas com as dietas 1; 2 e 3, respectivamente. Sabe-se que a relação C:N é importante medida de avaliação da possibilidade de degradação dos resíduos durante a compostagem; no entanto, mais importante do que as quantidades de carbono presentes no meio é a qualidade dessa fração, acarretando, assim, na maior ou na menor facilidade de degradação durante o processo. Nesse sentido, efetuou-se a quantificação dos conteúdos de FDN (fibra em detergente neutro, representada pelas constituintes de parede celular e que apresentam resistência à degradação) dos substratos empregados, obtendo-se os seguintes valores: 68,64; 63,30 e 59,40\% de FDN (com base nos teores de ST) em substratos provenientes dos dejetos de cabras Saanen, alimentadas com as dietas 1; 2 e 3, respectivamente, e 64,70; 61,20 e 58,40\% de FDN (com base nos teores de ST) em substratos provenientes dos dejetos de cabras F1, alimentadas com as dietas 1; 2 e 3, respectivamente.

Diariamente, foram monitoradas a temperatura e a umidade das leiras; semanalmente, efetuaram-se pesagens com medição do volume ocupado; nessa ocasião, foram feitos revolvimentos, avaliando-se os teores de sólidos totais (ST) e sólidos voláteis (SV), além da determinação dos NMPs (número mais provável) de coliformes totais e fecais no início e no final do processo.

Os teores de ST e SV foram determinados segundo metodologia descrita por APHA (1995). O NMP de coliformes totais e fecais foi avaliado por meio da técnica de tubos múltiplos, a partir da adaptação da metodologia descrita pela APHA (1995). A determinação do NMP de coliformes foi realizada em duas etapas (ensaio presuntivo e confirmativo). No ensaio presuntivo, semeou-se 1 $\mathrm{mL}$ de cinco diluições da amostra (efetuando-se previamente a diluição do material sólido em água peptonada), em séries, em três tubos de caldo lauryl triptose (CLT) simples para cada diluição. A partir desse procedimento, os tubos foram incubados a $35^{\circ} \mathrm{C}$, durante $48 \mathrm{~h}$. Quando houve produção de gás, cada cultura com resultado presuntivo positivo foi transferida para caldo lactosado com verde-brilhante e bile a $2 \%$ (CLVBB), sendo a incubação efetuada também a $35^{\circ} \mathrm{C}$, durante 48 h. Quando, novamente, ocorreu a produção de gás, dessa vez a partir da fermentação da lactose nesse meio, confirmou-se, então, a presença de bactérias do grupo coliforme. As culturas com resultados presuntivos positivos, nos ensaios de coliformes totais, foram transferidas para tubos contendo meio EC, que foram incubados durante $24 \mathrm{~h}$ a $45,5^{\circ} \mathrm{C}$ em banho-maria. $\mathrm{O}$ resultado foi considerado positivo quando houve produção de gás a partir da fermentação da lactose contida no meio EC.

As determinações dos conteúdos de FDN foram efetuadas conforme metodologias propostas no AOAC (1980).

Para a avaliação dos resultados gerados, adotou-se o delineamento inteiramente casualizado, em esquema fatorial, constando de seis tratamentos (três dietas x dois genótipos e três repetições (leiras)), com comparação de médias pelo teste de Tukey, a 5\% de probabilidade. Para a comparação das médias das variáveis, utilizou-se do SAS (1990).

\section{RESULTADOS E DISCUSSÃO}

As maiores reduções $(\mathrm{P}<0,05)$ das quantidades de massa seca (Tabela 2$)$ ocorreram em leiras formadas com os dejetos gerados quando as cabras foram alimentadas com a dieta 3 (média de $56,2 \%$ ), em relação aos dejetos gerados quando consumiram as dietas 2 (média de 44,5\%) e 1 (média de 40,6\%). Esse fato pode ser associado à maior participação de alimento concentrado na dieta, proporcionando dejetos com maior facilidade de degradação, provavelmente devido à menor concentração de fração fibrosa nas fezes, conforme os valores de FDN apresentados anteriormente. 
TABELA 2. Quantidades (kg) de matéria natural e sólidos totais, porcentagem (\%) de sólidos totais e voláteis e redução da quantidade de ST no início, aos 30; 60 e 90 dias de formação das leiras.

\begin{tabular}{|c|c|c|c|c|c|}
\hline \multirow{2}{*}{ Período } & MN (kg) & $\% \mathrm{ST}$ & ST (kg) & Redução ST (\%) & $\% \mathrm{SV}$ \\
\hline & \multicolumn{5}{|c|}{ D1 S } \\
\hline Formacão & 569,13 & 27,41 & 156,00 & & 88,28 \\
\hline 30 & 313,64 & 34,20 & 107,26 & 31,24 & 85,88 \\
\hline 60 & 243,69 & 40,70 & 99,18 & 36,42 & 82,76 \\
\hline \multirow[t]{2}{*}{90} & 200,44 & 46,12 & 92,44 & $40,74 \mathrm{Bb}$ & 80,50 \\
\hline & \multicolumn{5}{|c|}{ D1 F1 } \\
\hline Formação & 395,68 & 26,10 & 103,27 & & 90,41 \\
\hline 30 & 214,08 & 34,40 & 73,64 & 28,69 & 85,00 \\
\hline 60 & 193,91 & 33,48 & 64,92 & 37,14 & 83,78 \\
\hline \multirow[t]{2}{*}{90} & 165,26 & 37,25 & 61,56 & $40,39 \mathrm{Bb}$ & 82,37 \\
\hline & \multicolumn{5}{|c|}{ D2 S } \\
\hline Formação & 515,33 & 25,80 & 132,96 & & 87,24 \\
\hline 30 & 303,21 & 29,70 & 90,05 & 32,27 & 79,37 \\
\hline 60 & 231,78 & 34,60 & 80,20 & 39,68 & 76,35 \\
\hline \multirow[t]{2}{*}{90} & 181,62 & 40,40 & 73,37 & $44,81 \mathrm{Bb}$ & 76,13 \\
\hline & \multicolumn{5}{|c|}{ D2 F1 } \\
\hline Formação & 330,49 & 31,30 & 103,44 & & 89,61 \\
\hline 30 & 227,39 & 33,10 & 75,27 & 27,24 & 82,53 \\
\hline 60 & 173,04 & 36,58 & 63,30 & 38,81 & 80,45 \\
\hline \multirow[t]{2}{*}{90} & 143,76 & 40,15 & 57,72 & $44,20 \mathrm{Bb}$ & 78,95 \\
\hline & \multicolumn{5}{|c|}{ D3 S } \\
\hline Formação & 547,35 & 28,30 & 154,90 & & 89,29 \\
\hline 30 & 265,05 & 38,70 & 102,57 & 33,78 & 78,65 \\
\hline 60 & 194,25 & 42,00 & 81,59 & 47,33 & 75,67 \\
\hline \multirow[t]{2}{*}{90} & 139,16 & 48,20 & 67,08 & $56,70 \mathrm{Aa}$ & 72,66 \\
\hline & \multicolumn{5}{|c|}{ D3 F1 } \\
\hline Formação & 326,89 & 32,00 & 104,60 & & 87,72 \\
\hline 30 & 169,19 & 41,00 & 69,37 & 33,69 & 81,87 \\
\hline 60 & 124,63 & 45,61 & 56,84 & 45,66 & 78,74 \\
\hline 90 & 91,57 & 50,56 & 46,30 & $55,74 \mathrm{Aa}$ & 74,61 \\
\hline
\end{tabular}

S - Saanen e F1- cabras resultantes do cruzamento entre Saanen e Boer. Na coluna, letras maiúsculas comparam dietas e minúsculas genótipos. Médias seguidas de mesma letra não diferem entre si, pelo Teste de Tukey $(\mathrm{P}>0,05)$.

KIEHL (1985) considerou que a redução de massa seca esperada durante a compostagem, para materiais com relação C: $\mathrm{N}$ inicial entre 25 e 50:1, seria de 50\%; no entanto, essa quantidade está diretamente relacionada com a qualidade do material que será compostado, esperando-se reduções maiores em substratos de fácil degradação ou com menores quantidades de fração fibrosa. HSU \& LO (2001) efetuaram a compostagem dos dejetos de suínos e observaram que a maior perda de massa seca enleirada ocorreu durante os primeiros 18 dias de compostagem e que, a partir dos 50 dias, a taxa de decomposição da matéria orgânica foi extremamente baixa. Esse comportamento também foi observado durante a realização deste trabalho, ou seja, as maiores reduções de massa seca ocorreram durante os primeiros 30 dias de compostagem, independentemente do tratamento, e a partir dos 60 dias, as perdas foram minimizadas. Provavelmente, essa ocorrência esteja relacionada com a natureza dos resíduos que, por conservarem parte da alimentação ofertada aos animais, apresentam constituintes com facilidade de degradação.

AMORIM et al. (2005) efetuaram a compostagem dos dejetos de cabras Saanen durante as estações do ano e observaram reduções de 53,7; 53,4; 51,4 e 47,8\% de massa seca enleirada no 
verão, outono, inverno e primavera, respectivamente. As reduções obtidas em leiras originadas dos dejetos produzidos por cabras (Saanen e F1), alimentadas com dieta contendo $60 \%$ de concentrado, foram mais próximas às observadas pelos autores durante as estações de verão e outono.

Os resultados permitem observar que a maior média da temperatura semanal ocorreu na primeira semana, em leiras formadas a partir dos dejetos de cabras que consumiram a dieta 3 (Tabela 3), enquanto esse comportamento foi observado somente na segunda semana, quando o substrato utilizado foi o resultante dos dejetos de cabras que consumiram as dietas 1 e 2 . Observase, ainda, que as leiras originadas da dieta 1 mantiveram a temperatura superior por mais tempo (média de $50,8^{\circ} \mathrm{C}$ na terceira semana), em relação às originadas de cabras alimentadas pelas dietas 2 e 3 (médias de 45,9 e $42,0^{\circ} \mathrm{C}$, respectivamente, no mesmo período). Esses resultados apresentam o mesmo comportamento observado na redução de massa seca, que foi semelhante $(\mathrm{P}<0,05)$ para os substratos originários das dietas 1 e 2 , e distinto para os oriundos da dieta 3.

TABELA 3. Temperaturas médias semanais das leiras de compostagem formadas a partir dos dejetos de cabras adultas, Saanen e F1 (Saanen x Boer), alimentadas por três dietas, com variação na proporção entre volumoso e concentrado.

\begin{tabular}{ccccccc}
\hline Semanas & S D1 & F1 D1 & S D2 & F1 D2 & S D3 & F1 D3 \\
\hline 1 & 48,1 & 45,9 & 46,4 & 49,8 & 54,3 & 53,2 \\
2 & 58,7 & 55,1 & 57,0 & 56,0 & 53,0 & 50,1 \\
3 & 53,5 & 48,0 & 46,1 & 45,7 & 43,4 & 40,6 \\
4 & 36,2 & 33,6 & 33,9 & 35,5 & 31,6 & 31,6 \\
5 & 21,9 & 21,4 & 26,2 & 32,1 & 31,0 & 25,0 \\
6 & 19,2 & 19,3 & 25,3 & 31,0 & 25,8 & 22,8 \\
7 & 18,7 & 19,7 & 22,8 & 23,9 & 23,0 & 22,0 \\
8 & 21,0 & 20,8 & 21,8 & 20,6 & 19,9 & 20,3 \\
9 & 20,4 & 20,4 & 21,9 & 20,6 & 21,2 & 20,8 \\
10 & 20,6 & 20,1 & 19,4 & 20,9 & 19,5 & 19,8 \\
11 & 21,0 & 21,0 & 21,3 & 20,2 & 21,3 & 21,2 \\
12 & 20,1 & 21,0 & 21,6 & 20,9 & 21,1 & 20,9 \\
\hline
\end{tabular}

S - Saanen e F1- cabras resultantes do cruzamento entre Saanen e Boer.

A manutenção da temperatura na faixa termofílica durante a compostagem também foi verificada por THAMBIRAJAH et al. (1995), ao obterem temperaturas abaixo de $40{ }^{\circ} \mathrm{C}$ somente após os primeiros 25 dias de compostagem, a partir dos resíduos de extração de óleo de palma e dejetos de caprinos (90:25 kg, respectivamente).

JEONG \& KIM (2001) compostaram resíduos de alimentos e observaram que a fase termofílica teve duração superior a 10 dias e que, nos primeiros 20 dias de compostagem, houve perda de 45\% da massa enleirada. Em experimento conduzido por GEORGACAKIS et al. (1996), foram confeccionadas leiras compostas de esterco suíno, resíduos de algodão e peles de sementes, e obtidas temperaturas entre 45 e $55^{\circ} \mathrm{C}$ durante os primeiros 23 dias de compostagem.

Um importante parâmetro a ser observado é a manutenção da temperatura na faixa considerada termofílica $\left(45\right.$ a $65^{\circ} \mathrm{C}$ ), visto que essa temperatura é responsável pela eliminação de vários microrganismos patogênicos.

Os NMPs de coliformes totais e fecais (Tabela 4) encontrados no material de formação das leiras e no produto final demonstram a importância e a eficiência do processo de compostagem na redução desses patógenos, pois, independentemente do tratamento, as reduções não diferiram entre si e foram de, no mínimo, 99,99\%.

A redução do número de patógenos no produto final, que será retornado ao solo, é um fator importante, pois a ocorrência de altos níveis de bactérias do grupo coliforme na água de consumo pode sujeitar as propriedades a maiores taxas de incidência de doenças nos animais, com conseqüente aumento da mortalidade e diminuição da produtividade (ENNIX, 1996). 
TABELA 4. Números mais prováveis (NMP) de coliformes totais e fecais no material de formação e do produto final das leiras de compostagem formadas a partir dos dejetos de cabras adultas, Saanen e F1 (Saanen x Boer), alimentadas por três dietas, com variação na proporção entre volumoso e concentrado.

\begin{tabular}{lcccccc}
\hline & \multicolumn{6}{c}{ Tratamentos } \\
\cline { 2 - 6 } & D1 S & D1 F1 & D2 S & D2 F1 & D3 S & D3 F1 \\
\hline Formação & $5,810^{8}$ & $9,310^{8}$ & $2,910^{7}$ & $2,410^{10}$ & $2,410^{8}$ & $2,410^{9}$ \\
Final & 52,8 & 82,5 & 469,55 & 330 & 131,5 & 240 \\
\hline Redução (\%) & $100,00 \mathrm{Aa}$ & $99,99 \mathrm{Aa}$ & $99,99 \mathrm{Aa}$ & $100,00 \mathrm{Aa}$ & $99,99 \mathrm{Aa}$ & $99,99 \mathrm{Aa}$ \\
\hline \multicolumn{7}{c}{ Coliformes fecais (NMP por grama) } \\
\hline Formação & $5,810^{8}$ & $9,310^{8}$ & $2,910^{7}$ & $4,86510^{9}$ & $2,410^{8}$ & $1,7510^{9}$ \\
Final & 50,6 & 69,5 & 226,5 & 216,8 & 6,35 & 16 \\
\hline Redução (\%) & 100,00 Aa & 99,99 Aa & 99,99 Aa & 100,00 Aa & 100,00 Aa & 100,00 Aa \\
\hline S - Saanen e F1- cabras resultantes do cruzamento entre Saanen e Boer. Na linha, letras maiúsculas comparam dietas e
\end{tabular}

Segundo as tendências de redução de volume observadas (Tabela 5), nota-se que o comportamento foi bastante semelhante para todas as situações, independentemente do substrato que originou as leiras ou mesmo do volume ocupado. As equações originadas desses valores apresentaram $\mathrm{R}^{2}$ elevados, significando que os resultados obtidos são de elevada confiabilidade.

As equações que estimam a redução de volume considerando o período de formação das leiras são valiosas para o planejamento de áreas destinadas à compostagem, com subseqüente melhoria de utilização do espaço.

TABELA 5. Volume ocupado $\left(\mathrm{m}^{3}\right)$ por leiras formadas a partir dos dejetos de cabras adultas, Saanen e F1 (Saanen x Boer), alimentadas por três dietas, com variação na proporção entre volumoso e concentrado

\begin{tabular}{ccccccc}
\hline \multirow{2}{*}{ Semanas } & D1 S & D1 F1 & D2 S & D2 F1 & D3 S & D3 F1 \\
\cline { 2 - 6 } & \multicolumn{5}{c}{ Volume $\left(\mathrm{m}^{3}\right)$} \\
\hline 0 & 1,22 & 0,78 & 1,12 & 0,79 & 0,92 & 0,71 \\
1 & 1,12 & 0,75 & 0,99 & 0,75 & 0,87 & 0,61 \\
2 & 1,00 & 0,67 & 0,90 & 0,66 & 0,80 & 0,61 \\
3 & 0,93 & 0,64 & 0,82 & 0,63 & 0,73 & 0,54 \\
4 & 0,87 & 0,59 & 0,79 & 0,62 & 0,69 & 0,52 \\
5 & 0,82 & 0,57 & 0,76 & 0,59 & 0,66 & 0,50 \\
6 & 0,77 & 0,55 & 0,71 & 0,56 & 0,63 & 0,47 \\
7 & 0,73 & 0,54 & 0,69 & 0,55 & 0,62 & 0,47 \\
8 & 0,72 & 0,52 & 0,65 & 0,51 & 0,57 & 0,44 \\
9 & 0,71 & 0,51 & 0,62 & 0,51 & 0,56 & 0,43 \\
10 & 0,67 & 0,49 & 0,57 & 0,47 & 0,55 & 0,42 \\
11 & 0,66 & 0,48 & 0,54 & 0,45 & 0,51 & 0,40 \\
12 & 0,64 & 0,45 & 0,53 & 0,45 & 0,48 & 0,37 \\
\hline
\end{tabular}

D1 S $\quad y=0,0044 x^{2}-0,097 x+1,1983\left(R^{2}=99,16\right)$

D1 F1 $y=0,0021 x^{2}-0,0502 x+0,7782\left(R^{2}=98,31\right)$

D2 S $\quad y=0,0029 x^{2}-0,0788 x+1,0742\left(R^{2}=98,09\right)$

D2 F1 $y=0,0016 x^{2}-0,0462 x+0,778\left(R^{2}=98,14\right)$

D3 S $y=0,0021 x^{2}-0,0598 x+0,9114\left(R^{2}=99,06\right)$

D3 F1 $y=0,0017 x^{2}-0,0448 x+0,6801\left(R^{2}=97,15\right)$

$\mathrm{Y}=$ volume $\left(\mathrm{m}^{3}\right)$ ocupado pelas leiras e $\mathrm{x}=$ semanas de formação das leiras 


\section{CONCLUSÕES}

As reduções de massa seca, coliformes totais e fecais, assim como do volume ocupado pelas leiras foram maiores quanto maior a adição de concentrado, em restrição ao volumoso, nas dietas com as quais foram alimentadas cabras Saanen e F1.

Esses resultados são importantes para que haja adequação da atual tendência da produção animal, sobretudo no Estado de São Paulo, que consiste na alimentação de animais com maiores quantidades de alimento concentrado, em relação ao planejamento de reciclagem dos dejetos. Dessa forma, os benefícios da alimentação, além da melhoria do desempenho zootécnico dos animais, podem ser estendidos à melhoria dos índices esperados para a compostagem.

\section{AGRADECIMENTOS}

Ao Conselho Nacional de Desenvolvimento Científico e Tecnológico (CNPq), pela concessão da bolsa de doutorado, e à Fundação de Amparo à Pesquisa do Estado de São Paulo (FAPESP), pelo auxílio à pesquisa.

\section{REFERÊNCIAS}

APHA. AMERICAN PUBLIC HEALTH ASSOCIATION. Standard methods for the examination of water and wastewater. $19^{\text {th }}$ ed. Washington, 1995. "pg. irreg."

AMORIM, A.C.; LUCAS JÚNIOR, J.; RESENDE, K.T. Utilização de dejetos produzidos por caprinos como substrato para os processos de compostagem e vermicompostagem. Engenharia Agrícola, Jaboticabal, v.25, n.1, p.57-66, 2005.

AOAC. ASSOCIATION OF OFFICIAL ANALYTICAL CHEMISTS. Official methods of analysis $13^{\text {th }}$ ed. Washington, 1980. $1.011 \mathrm{p}$.

EL AICH, A.; WATERHOUSE, A. Small ruminants in enviromental conservation. Small Ruminant Research, Thessaloniki, v.34, n.2, p.271-87, 1999.

ENNIX INC. Product Guide. Arizona, 1996. 327 p. Manual da Empresa

GEORGACAKIS, D.; TSAVDARIS, A.; BAKOULI, J.; SYMEONIDIS, S. Composting solid swine manure and lignite mixture with selected plant residues. Bioresource Technology, Oxford, v.56, n.2, p.195-200, 1996.

GOMEZ, A. The evaluation of compost quality. Trends in Analytical Chemistry, Aldershot, v.17, n.16, p.310-14, 1998

HANAJIMA, D.; KURODA, K.; HAFGA, K. Enhancement of the thermophilic stage in cattle waste composting by addition of the tofu residue. Bioresource Technology, Oxford, v.78, n.2, p.213-16, 2001.

HSU, J.H.; LO, S.L. Effect of composting on characterization and leaching of copper, manganese and zinc from swine manure. Environmental Pollution, Amherst, v.114, n.1, p.119-27, 2001.

IMBEAH, M. Composting piggery waste: a review. Bioresource Technology, Oxford, v.63, n.3, p.197-203, 1998.

JEONG, Y.K.; KIM, J.S. A new method for conservation of nitrogen in aerobic composting process. Bioresource Technology, Oxford, v.79, n.2, p.129-133, 2001.

KIEHL, E.J. Fertilizantes orgânicos. São Paulo: Agronômica Ceres, 1985. 492 p.

NRC. NUTRITION REQUERIMENTS OF GOATS. Washington: National Academy Press, 1981. p.2-3.

PEREIRA NETO, J.T.; STENTIFORD, E.I. Aspectos epidemiológicos da compostagem. Revista de Biologia, Uberlândia, v.1, n.1, p.1-6, 1992. 
RIBEIRO, S.D.A.; RIBEIRO, A.C. Produção de carne caprina: situação atual e perspectivas. In: REUNIÃO ANUAL DA SOCIEDADE BRASILEIRA DE ZOOTECNIA, 38., 2001, Piracicaba. Anais... SBZ, 2001. p.504-12.

SAS. SAS/STAT. User's Guide, Version 6. $4^{\text {th }}$ ed. Cary, 1990. 891 p.

THAMBIRAJAH, J.J.; ZULKALI, M.D.; HASHIM, M.A. Microbiological and biochemical changes during the composting of oil palm empty-fruitbunches. Effect of nitrogen supplementation on the substrate. Bioresource Technology, Oxford, v.52, n.52, p.133-44, 1995.

USEPA. US ENVIRONMENTAL PROTECTION AGENCY. Environmental indicators of quality in the United States, 1996. EPA 841-R-96-002. 